\title{
Apex Ear Bloodletting, Dietary Counseling and Psychotropic Medication in Patients with Anxiety Treated with Auricular Acupuncture - A Double Blind Study
}

\author{
Huang, W. L* \\ MD Infectious Disease Specialist, General Practice, Nutrition Doctor, Acupuncture, Pain Management \\ Specialist, Medical Acupuncture and Pain Management Clinic, Franca, São Paulo, Brazil
}

*Corresponding Author: Huang, W. L, MD Infectious Disease Specialist, General Practice, Nutrition Doctor, Acupuncture, Pain Management Specialist, Medical Acupuncture and Pain Management Clinic, Franca, São Paulo, Brazil, Email: weilingmg@gmail.com

\begin{abstract}
Introduction: Anxiety is a worldwide problem, which has been increasing in the past 30 years. In TCM, anxiety disorders are understood as a disorder of Shan You Si or Yu Zhen, not seen as a brain dysfunction, but as an inner organs' dysfunction. We are reporting an original observation of PFP revealing NF1 in adult subject.

Purpose: The purpose of this study is toshow the effectiveness of apex ear bloodletting, Chinese dietary counselling, and use of psychotropic medication in anxiety patients treated with auricular acupuncture.The methodology used was the study of theories from ancient medical traditions, such as Traditional Chinese Medicine, which explain all symptoms and diseases as imbalances in internal energies. These energies are Yin, Yang, Qi and Blood. Their imbalances could create internal Heat, also responsible for anxiety symptoms in TCM. A double-blind study was done with more than 1500 records of the author's clinic in Brazil,97 or $6.5 \%$ of these patients reported anxiety symptoms. All these patients were contact and 46 or $3.06 \%$ of the total were reached.
\end{abstract}

Finding: The reports showed that in relation to the recommendation or non-recommendation of their treatment for anxiety, $100 \%$ of patients would recommend Auricular Acupuncture for anxiety.

Conclusion: The patients submitted to auricular acupuncture associated with apex ear bloodletting showed almost three times more chance of improvement of anxiety symptoms, compared to the group that did not received apex ear bloodletting. Patients who did follow the dietary recommendations, specifically the avoidance of dairy products showed better results on treatment for anxiety symptoms compared to patients that did not follow the recommendations. The suspension of psychotropic medications during auricular acupuncture treatment was not important for improvement.

Keywords: Anxiety, Chinese Dietary Counselling, Auricular Acupuncture, Energy, Traditional Chinese Medicine, Apex Ear Bloodletting, Psychotropic Medications.

\section{INTRODUCTION}

Anxiety is described as "a diffuse, unpleasant, vague sense of apprehension" [1-2]. The symptom is often a response to an imprecise or unknown threat. Usually, it comes from the mind's vision of possible dangers and treats in common situations [1-2]. It is a common feeling among Western patients, and can be accompanied by fear and constant worry, which are two of the seven emotions treated in Traditional Chinese Medicine (TCM).[1-2]

The case that originated the logic of the treatment, as previously stated in other studies of the author, was from a patient that presented symptoms of leg pain. This patient searched for the author's clinic after performing treatment with general anti-inflammatory for the pain without any improvement. The author then started a treatment with Chinese dietary counseling, systemic and auricular acupuncture, and performed the diagnosis of the patient in Traditional Chinese Medicine. [3-7]

The patient was diagnosed with Kidney-Yang deficiency, and the treatment was started for treating this energy imbalance. [3-7]

After 10 sessions of acupuncture, the patient returned to be reevaluated, and told the author he had perceived great improvement not only of 
his leg pain symptoms, but also great diminution in his intraocular pressure. The author was not aware, but the patient was bearer of glaucoma, and was performing treatment with Western Medicine drugs and eye drops for 40 years, without significant improvement in his condition, always with the intraocular pressure appearing around $40 \mathrm{mmHg}$. After the 10 sessions of acupuncture, his intraocular pressure diminished to $17 \mathrm{mmHg}$, for the first time in his life. [3-7]

The author observed the results in this patient, and used it in the treatment of several other patients and pathologies, including in this case anxiety.

\section{Purpose}

The purpose of this study is to show the effectiveness of apex ear bloodletting, Chinese dietary counseling, and use of psychotropic medication in anxiety patients treated with auricular acupuncture.

\section{METHODS}

The methods used in this research based in a double-blind study of patients records.

From more than 1500 patients from the clinic, 97 or $6.5 \%$ reported anxiety symptoms. All these patients were contact and 46 or $3.06 \%$ of the total were reached. Their energy disturbances according to TCM were noted.

A questionnaire was filled by phone, including a Hospital Anxiety Evaluation Scale (HAES) test, and the patients were invited to answer the differences between before and after the auricular acupuncture treatment.

To evaluate the degree of anxiety we used this Hospital Anxiety Evaluation Scale (HAES), represented in Figure 1.

The questionnaire was filled twice during the same interview, asking about his anxiety symptoms, before and after acupuncture treatment.

\begin{tabular}{|c|c|c|c|c|}
\hline \multicolumn{5}{|c|}{ Hospital Anxiety } \\
\hline & $\begin{array}{c}\text { Yes } \\
\text { definitely }\end{array}$ & $\begin{array}{c}\text { Yes } \\
\text { sometimes }\end{array}$ & $\begin{array}{l}\begin{array}{c}\text { No, not } \\
\text { much }\end{array} \\
\end{array}$ & $\begin{array}{c}\text { No, not } \\
\text { at all }\end{array}$ \\
\hline $\begin{array}{l}\text { 2. I get very frightened or have panic } \\
\text { feelings for apparently no reason at all. }\end{array}$ & 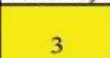 & 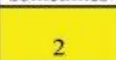 & 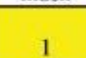 & 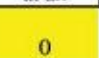 \\
\hline $\begin{array}{l}\text { 4. I feel anxious when I go out of the } \\
\text { house on my own. }\end{array}$ & 3 & 2 & 1 & 0 \\
\hline $\begin{array}{l}\text { 6. I get palpitations, or sensations of } \\
\text { 'butterflies' in my stomach or chest. }\end{array}$ & 3 & 2 & 1 & 0 \\
\hline 8. I feel scared or frightened. & 3 & 2 & 1 & 0 \\
\hline 11. I am restless and can't keep still. & 3 & 2 & 1 & 0 \\
\hline 12. I am more irritable than usual. & 3 & 2 & 1 & 0 \\
\hline $\begin{array}{l}\text { 14. Worrying thoughts constantly go } \\
\text { through my mind. }\end{array}$ & 3 & 2 & 1 & 0 \\
\hline
\end{tabular}

Figure1. Hospital Evaluation Scale (HAES)

There are seven questions and the total indicates the degree of anxiety. The answer is based on a scale of zero and seven, 0 indicating no anxiety. Eight to ten, indicates a borderline situation. A score of eleven or more is considered anxiety.

The evaluation consisted on the number of sessions necessary to show improvement, the effectiveness of this treatment, dietary recommendations, and the patient's possible history of neurological or psychiatric treatment. The use of psychotropic medications was also analyzed, considering the time of use, and if they stopped using their medication during acupuncture treatment. The questionnaire also evaluated the use of apex ear bloodletting and the difference at the results.

\section{FINDINGS}

Most of patients were females, more than three quarters $(75 \%)$. Less than quarters were males. For males, the distribution of those who felt anxious were quite even, but for the females there were more young adults, than middle aged, before the time of menopause. After menopause, there were fewer women with anxiety.

According to TCM, this can be explained because before menopause, the monthly period can cause blood deficiency and consequently Internal Heat formation, generating anxiety symptoms. As in menopause, women no longer menstruate, the risk of forming Internal Heat decreases, leading to fewer patients with anxiety symptoms. 
The results also showed $60 \%$ of patients didn't have any medical care before the auricular acupuncture treatment. From the $40 \%$ who did, $43 \%$ had seen a neurologist, and $57 \%$ had seen a psychiatrist.

In this chart presented in Figure 2, it is possible to observe the use of psychotropic medication among the studied patients. $60 \%$ had not taken any medication. Of the $40 \%$ who did, $15 \%$ were taking an anxiolytic, $42.5 \%$ were taking an antidepressant, and $42.5 \%$ were taking both the anxiolytic and antidepressant medications.

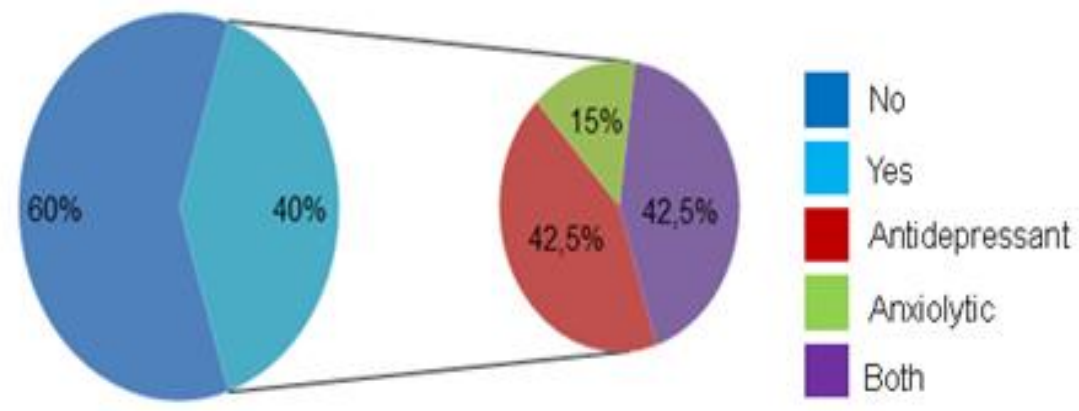

Figure2. Use of psychotropic medication among patients who underwent AA treatment for anxiety

The majority of them (more than 62\%), had been under medication for more than 12 months. Two groups of $15 \%$ had been using medication for 4-6 months, and 7\% for 12 months exactly. Only a small percentage had been using medication for 1-3 months. More than half of the patients studied received apex ear bloodletting treatment.

Many patients claimed to have followed the Chinese dietary recommendations during their auricular acupuncture treatment. 80\% claimed that they had followed them. The other $20 \%$ didn't.

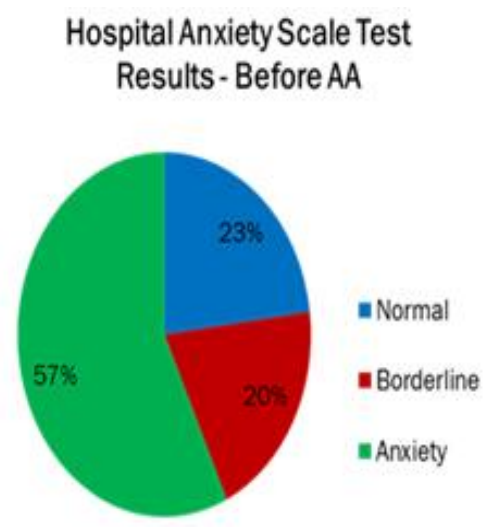

Figure3. Comparison of percentage of patients with anxiety before and after AA

Also, regarding the Hospital Anxiety Evaluation Scale, we can see the influence of apex ear bloodletting during the treatment. Usually, this procedure is not recommended to anxiety. The parameter used was the migration of patients to the one level to another. Of the total, $57 \%$ received apex ear bloodletting, and $43 \%$ did not. From the patients who migrated from Anxiety to Borderline or Normal, or Borderline to Normal, we can see that $70 \%$ improved, and $30 \%$ did
The results of the first questionnaire, made before the start of the acupuncture treatment, showed $23 \%$ as normal, $20 \%$ as borderline, and $57 \%$ as pathologically anxious.

The second questionnaire, made after the acupuncture treatment, showed $63 \%$ as normal, $17 \%$ as borderline and $20 \%$ as pathologically anxious. Therefore, the number of pathologically anxious patients was reduced in $37 \%$, as represented in Figure 3.

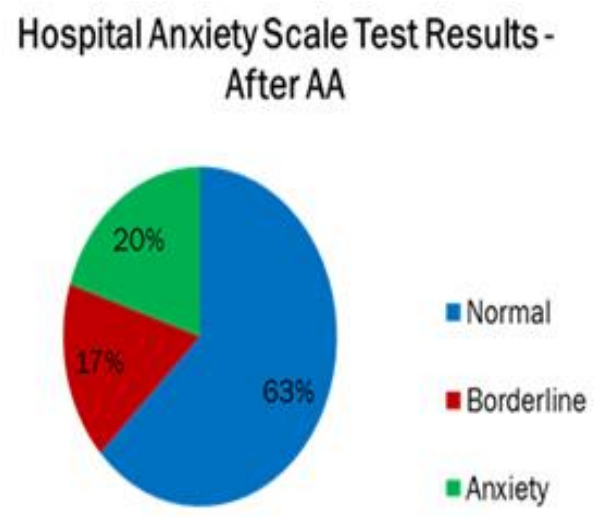

not. In relation to those who did not do the Apex Ear Bloodletting, only $27 \%$ showed improvement, and $73 \%$ did not.

In Figure 4, the chart shows the influence of the diet in the results of the auricular acupuncture treatment. In these recommendations, even though we had to make many alterations in the diet, we focused on the restriction of dairy products. 
Apex Ear Bloodletting, Dietary Counseling and Psychotropic Medication in Patients with Anxiety Treated with Auricular Acupuncture - A Double Blind Study

\begin{tabular}{|c|c|c|c|c|c|c|c|}
\hline \multirow[b]{2}{*}{$\begin{array}{l}\text { Initial State } \\
\text { Before } \\
\text { Treatment }\end{array}$} & \multirow{2}{*}{$\begin{array}{l}\text { Total of } \\
\text { Patients } \\
\text { Before } \\
\text { Treatment }\end{array}$} & \multirow[b]{2}{*}{$\begin{array}{c}\text { Final State } \\
\text { After } \\
\text { Treatment }\end{array}$} & \multirow{2}{*}{$\begin{array}{c}\text { Total of } \\
\text { Patients } \\
\text { After } \\
\text { Treatment }\end{array}$} & \multicolumn{4}{|c|}{$\begin{array}{l}\text { Following Dietary Recommendations (DR)/Avoiding } \\
\text { Dairy Products }\end{array}$} \\
\hline & & & & Yes & $\begin{array}{l}\text { \% in relation } \\
\text { to the total } \\
\text { that followed } \\
\text { DR ( } 28 \\
\text { patients }-80 \%)\end{array}$ & No & $\begin{array}{l}\% \text { in relation to the total } \\
\text { that did not follow the } \\
\text { DR (7patients - 20\%) }\end{array}$ \\
\hline \multirow{3}{*}{ Anxiety. } & \multirow{3}{*}{20} & Anxiety & 7 & 4 & $14.29 \%$ & 3 & $42.86 \%$ \\
\hline & & Borderline & 4 & 4 & $14.29 \%$ & 0 & $0.00 \%$ \\
\hline & & Normal & 9 & 7 & $25.00 \%$ & 2 & $28.57 \%$ \\
\hline \multirow{2}{*}{ Borderfine } & \multirow{2}{*}{7} & Borderline & 2 & 1 & $3.57 \%$ & 1 & $14.29 \%$ \\
\hline & & Normal & 5 & 4 & $14.29 \%$ & 1 & $14.29 \%$ \\
\hline Normal & 8 & Normal & 8 & 8 & $28.57 \%$ & 0 & $0.00 \%$ \\
\hline Total & 35 & & 35 & 28 & $100.00 \%$ & 7 & $100.00 \%$ \\
\hline
\end{tabular}

Figure4. Anxiety treatment results associated or not with dietary recommendations/avoiding dairy products

Of the total, $53 \%$ of those who followed the dietary recommendations had some improvement, and $43 \%$ who did not follow.

The chart represented in Figure 5 shows the influence of the use and of the withdrawn of the psychotropic medication during the treatment with auricular acupuncture. Of the total $40 \%$ were using medication, and $60 \%$ were not. From the group that was using medication, more than $35 \%$ stopped during their auricular acupuncture treatment, but $64 \%$ persisted with the use.

Comparing these two groups of patients, $60 \%$ of those who stopped their medication use , had some improvement, compared to $67 \%$ who did not stop their medication.

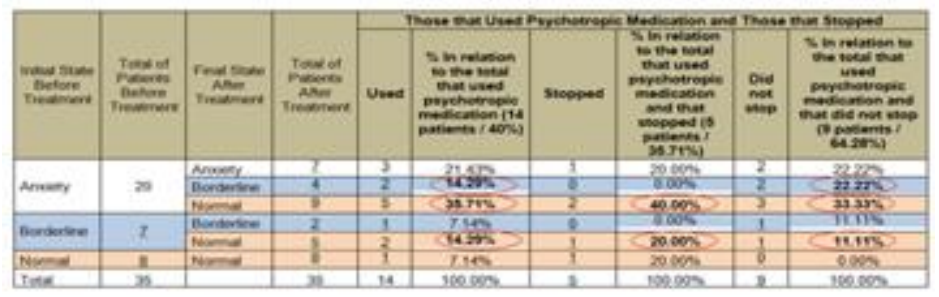

Figure5. Anxiety treatment results associated or not with the use of psychotropic medication

The chart presented in the Figure 6, shows how patients evaluated their treatment. There were three options of answers: Feeling cured, feeling improving, feeling not cured. During the study, $85 \%$ of the patients felt improvement, and almost $6 \%$ felt cured. The rest, or three patients, claimed that they felt no improvement in their condition. What all three patients had in common was the lack of apex ear bloodletting in their treatment.
As apex ear bloodletting is precisely to take away the internal Heat buildup, which causes the anxiety symptoms, the lack of the use of this procedure in the treatment, maintains the internal heat, even with the use of the auricular points to balance energy, maintaining the condition. in relation to the recommendation or non-recommendation of their treatment for anxiety, $100 \%$ of patients would recommend Auricular Acupuncture for anxiety.

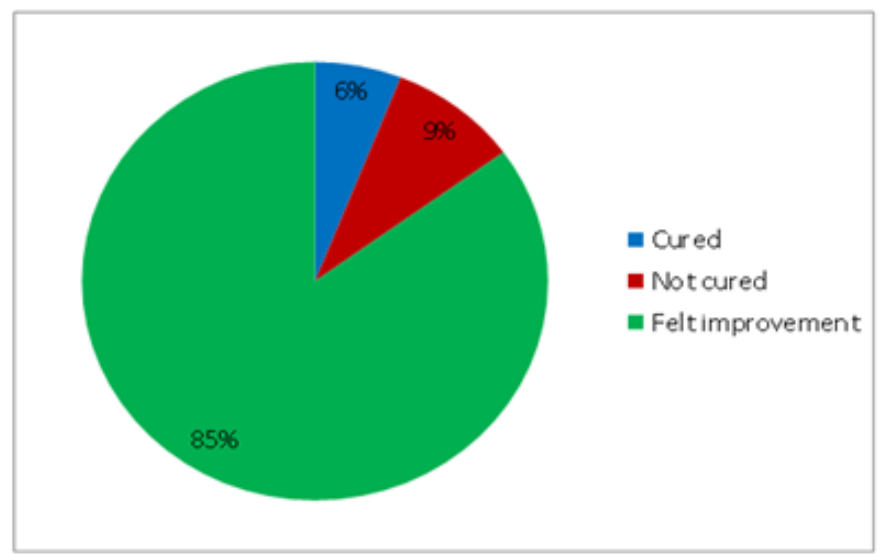

Figure6. Patient evaluation of their AA treatment for anxiety: Cured, not-cured or improved 


\section{DISCUSSION}

On literature, apex ear bloodletting is not usually recommended for the treatment of anxiety symptoms. This research demonstrated the opposite and the necessity of doing apex ear bloodletting to improve anxiety symptoms. [8-9, 12, 14-15]

The consumption of dairy products is believed to imbalance the Spleen-pancreas meridian, which is responsible for energy absorption and production of Blood, when the Spleen-pancreas meridian is imbalanced, other meridians will be imbalanced as well. Sometimes the patient consumes dairy products without even knowing, as there are dairy related ingredients in different types of food. Even though, there was significant difference in the results of patients who declared to stop the consumption of dairy products. [3-7, 10]

Regarding the use of psychotropic medication, the author analyzed the difference between a group that withdrawn the medication for anxiety and a group that did not. There was no significant difference between the two groups, because the use of psychotropic medication is believed to harm vital energy, according to the Arndt-Schultz Law. The Arndt-Schultz law was extensively discussed by the author in other articles [3-7]. It is important to remember that the side effects of the medications were not evaluated in this study, such as memory loss or loss of focus, and the physicians have to consider these aspects when deciding for the use of psychotropic medications during treatment with acupuncture. According to the ArndtSchultz law, there may be a chance of developing other chronic disease in the future due to lack of vital energy, such as diabetes, myocardial infarction, hypertension, cancer, etc. [3-7]

In another study of the author entitled Apex Ear Bloodletting, Restriction of Dairy Products, Psychotropic Medication and Energy Disturbances in Patients with Depression Treated with Auricular Acupuncture - A Double Blind Study, the use of psychotropic medication in patients with depression was analyzed. The results were better when there was suspension of the medication use, because of the reduction of the vital energy, which may cause symptoms of depression on itself, simulating a depression condition. [16]
Acupuncture is considered a medical specialty by the Federal Medical Council since 1995. [37]

In other articles of the author, the use of highdiluted medications is preferred, such as homeopathy, quantum medications or crystalbased medications, as they are believed to improve vital energy and replenish the energy of the chakras. As well as reducing formation of Heat, and therefore, the levels of anxiety, with less side effects than the several associated with the use of psychotropic medication, considered high-concentrated medication. [3-7]

\section{CONClusion}

In this study, it was possible to conclude that more than $90 \%$ percent of the patients who had undergone auricular acupuncture for the treatment of anxiety symptoms, had felt an improvement.

From this group, $80 \%$ percent felt this improvement on the first month of treatment.

The patients that were submitted with auricular acupuncture associated with apex ear bloodletting showed almost three times more chance to improve anxiety symptoms, compared to the group that did not received apex ear bloodletting.

Patients who did follow the dietary recommendations, specifically the avoidance of dairy products showed better results on treatment for anxiety symptoms compared to patients that did not follow the recommendations.

The suspension of psychotropic medications during auricular acupuncture treatment was not important for improvement. In this study, we did not consider the side effects of this kind of medication that could influence the decision of maintaining or not the medication use. This could be a reason for more studies concerning this the main the future.

\section{ACKNOWLEDGMENT}

Thanks for the Marcio Benevides Lessa, professor of the Uni-Facef University, in Franca, São Paulo, Brazil, for the statistics and graphics displayed on the study.

\section{REFERENCES}

[1] Alexander Bystritsky, MD, PhD, Sahib S. Khalsa, MD, PhD, Michael E. Cameron, PhD, and Jason Schiffman, MD, MA, MBA.Current Diagnosis and Treatment of Anxiety Disorders. T. 2013 Jan; 38(1): 30-38, 41-44, 57. 
[2] Florence Thibaut.Anxiety disorders: a review of current literature. Dialogues Clin Neurosci. 2017 Jun; 19(2): 87-88.

[3] Huang Wei Ling. "Could Postsurgical Nosocomial Cellulitis be Treated without the Use of Antibiotics?". Acta Scientific Microbiology 1.9 (2018):

[4] Huang Wei Ling. "Can Recurrent Furunculosis be Treated without the Use of Antibiotics?". Acta Scientific Microbiology 1.9 (2018): 04-12.

[5] Huang W.L. Can Hospital Osteomyelitis Be Treated Without the Use of Antibiotics? Int J Microbiol Infect Dis. 2018; 2(1):1-6.

[6] Huang, W. L. Why do Patients Still Catch Hospital Infections Despite the Practice of Infection Prevention and Control Programs? Acta Scientific Microbiology (ISSN: 25813226), 2018. Volume 1 Issue 4.

[7] Huang, W.L. Why do Patients Still Have Diabetes Despite the use of Diet, Antiglycemic Medication and Insulim? Journal of Diabetes and Metabolic Disorders.

[8] Huang, L.C., Auricular Medicine, Huang Publ., 2005.
[9] Huang, L.C., Tratamiento Auricular, Formulas y Prescripciones, Publishedby: Centro Internacional de Investigacion y Entrenameinto em Medicina Auricular, 2002

[10] Kastner, J., Chinese Nutrition Therapy, Verlag, 2009.

[11] Lader, M.H., \& Uhde, T.U., Anxiety, Panic and Phobias, second Edition 2006

[12] Maciocia, G., Diagnósitico na Medicina Chinesa, Roca, 2006.

[13] Maciocia, G., Obstetrics and Gynecology in Chinese Medicine, Brazilian edition.

[14] Ross, Jeremy, Combinações dos Pontos de Acupuntura, ROCA, 2003.

[15] Wang, Liu Gong, Tratado Contemporaneo de Acupuntura e Moxibustao, CEIMEC, 2005.

[16] Huang, Wei Ling. Apex Ear Bloodletting, Restriction of Dairy Products, Psychotropic Medication andEnergy Disturbances in Patients with Depression Treated with Auricular Acupuncture - A Double Blind Study.Archives of Neurology and Neuro Disorders. 2019; 2(2): 31-42.

Citation: Huang, W. L, Apex Ear Bloodletting, Dietary Counseling and Psychotropic Medication in Patients with Anxiety Treated with Auricular Acupuncture - A Double Blind Study. ARC Journal of Neuroscience. 2019; 4(2):20-26. doi: dx.doi.org/10.20431/2456-057X 0402004.

Copyright: (C) 2019 Authors. This is an open-access article distributed under the terms of the Creative Commons Attribution License, which permits unrestricted use, distribution, and reproduction in any medium, provided the original author and source are credited. 